Parapemikir : Jurnal Ilmiah Farmasi Vol 9 No.2 Tahun 2020

\title{
Pola Penggunaan Obat Pada Pasien Dispepsia Rawat Jalan Di Rsud H.Abdul Manap Kota Jambi
}

\author{
Restu Gusti Mulandani*1, Armini Hadriyati ${ }^{2}$, Rahmadevi $^{3}$ \\ ${ }^{1,2,3}$ Program Studi Farmasi, STIKES Harapan Ibu, Jambi \\ e-mail: *1 restuallah1997@gmail.com
}

\section{Article Info}

Article history:

Submission Mei 2020

Accepted Juni 2020

Publish Juli 2020

\begin{abstract}
Abstrak
Dispepsia merupakan salah satu masalah pencernaan yang paling umum ditemukan di masyarakat. Gejala yang dirasakan seperti nyeri ulu hati, mual, muntah, nafsu makan berkurang, sendawa dan rasa cepat kenyang. Penelitian ini bertujuan untuk mengetahui pola penggunaan obat dispepsia pada pasien rawat jalan tahun 2017-2018 di Rumah Sakit Umum Daerah H. Abdul Manap Kota Jambi berdasarkan nama obat, jumlah obat perpasien, bentuk sediaan dan golongan obat. Penelitian ini merupakan penelitian deskriptif dengan menggunakan studi evaluasi pada data retrospektif dilakukan pada bulan Agustus 2019, data diperoleh dari rekam medik pasien dispepsia rawat jalan di Rumah Sakit Umum Daerah H. Abdul Manap Kota Jambi tahun 2017-2018 dengan metode purposive sampling. Data yang diperoleh disajikan dalam bentuk persentase, nilai rata-rata dan tabel. Hasil penelitian menunjukkan sebanyak 76 pasien tahun 2017 dan 81 pasien tahun 2018. Penyakit dispepsia paling banyak terjadi pada perempuan $(69,74 \%)$ tahun $2017,(69,14 \%)$ tahun 2018 dan pada usia 45-60 tahun (43,42\%) tahun 2017, (44,44\%) tahun 2018. Sediaan obat yang paling banyak digunakan tablet $(65,97 \%)$ tahun 2017, (66,10\%) tahun 2018. Berdasarkan golongan obat Pump Proton Inhibitor (Lansoprazole, Omeprazole) 50,66\% tahun 2017, 48,28\% tahun 2018 yang paling banyak digunakan untuk pengobatan dispepsia dengan manifestasi klinik yang paling banyak ditemukan yaitu nyeri epigastrium 27,63\% tahun 2017, 23,46\% tahun 2018
\end{abstract}

Kata kunci-Dyspepsia, rawat jalan, RSUD H. Abdul Manap Kota jambi

\section{Abstract}

Dyspepsia is one of the most common digestive problems found in society. Symptoms such as heartburn, nausea, vomiting, decreased appetite, belching and feeling full quickly. This study aims to determine the pattern of use of dyspepsia in outpatients in 2017-2018 in the H. Abdul Manap Regional General Hospital of Jambi City based on the name of the drug, the number of drug patients, dosage forms and drug classes. This research is a descriptive study using an evaluation study on retrospective data conducted in August 2019, data obtained from the medical records of outpatient dyspepsia patients in the H. Abdul Manap Regional General Hospital of Jambi City in 2017-2018 with the purposive sampling method. The data obtained are presented in the form of percentages, average values and tables. The results showed as many as 76 patients in 2017 and 81 patients in 2018. Dyspepsia was most common in women (69.74\%) in 2017, (69.14\%) in 2018 and at the age of 45-60 years (43.42\%) in 2017, (44.44\%) in 2018. The most widely used drug preparations tablets (65.97\%) in 2017, (66.10\%) in 2018. Based on the Pump Proton Inhibitor drug group (Lansoprazole, Omeprazole) 50, 66\% in 2017, 48.28\% in 2018 which was most widely used for the. treatment of dyspepsia with the most common clinical manifestations, namely epigastric pain $27.63 \%$ in 2017 , $23.46 \%$ in 2018 .

Keyword - Dyspepsia, outpatient, RSUD H. Abdul Manap Kota jambi 


\begin{tabular}{lr}
\hline Alamat korespondensi: & \\
Prodi DIII Farmasi Politeknik Harapan Bersama Tegal & p-ISSN: 2089-5313 \\
Gedung A Lt.3. Kampus 1 & e-ISSN: 2549-5062 \\
Jl. Mataram No.09 Kota Tegal, Kodepos 52122 & \\
Telp. (0283) 352000 & E-mail: parapemikir_poltek@yahoo.com
\end{tabular}




\section{A. Pendahuluan}

Dispepsia adalah suatu kondisi medis dengan tanda-tanda rasa sakit atau rasa tidak enak pada perut bagian atas atau ulu hati. Makan yang tidak teratur memicu timbulnya berbagai penyakit karena terjadi ketidak seimbangan dalam tubuh. Ketidakteraturan ini berhubungan dengan waktu makan. Biasanya, dispepsia berada dalam kondisi terlalu lapar namun kadang-kadang terlalu kenyang. Sehingga kondisi lambung dan pencernaannya menjadi terganggu [1]. Dispepsia merupakan salah satu masalah pencernaan yang paling umum ditemukan. Perubahan pola makan dan gaya hidup menjadi salah satu penyebab terjadinya masalah pencernaan ${ }^{[2]}$. Berdasarkan penelitian pada populasi umum didapatkan 15$30 \%$ orang dewasa pernah mengalami hal ini dalam beberapa hari. Diperkirakan angka insiden dispepsia antara 1-8\% ${ }^{[3]}$.

Perkembangan teknologi dan industri serta perbaikan sosial ekonomi telah membawa perubahan perilaku dan gaya hidup masyarakat serta situasi lingkungan seperti pola konsumsi makanan yang tidak seimbang, kurangnya aktivitas fisik dan meningkatnya polusi lingkungan. Perubahan tersebut telah memberi pengaruh terhadap terjadinya peningkatan kasus penyakit tidak menular salah satunya dispepsia (Pardiansyah, 2016).

Hasil penelitian Srikandi, Mukaddas dan Faustine (2017) tentang Pola Penggunaan Obat pada Pasien Dispepsia di RSU Anutapura Palu diketahui bahwa sebanyak 258 pasien dispepsia yang menggunakan jenis obat kelas terapi antiulkus yaitu antasida $29,96 \%$, lansoprazole 23,63\%, omeprazole 11,64\%, sukralfat $5,14 \%$, ranitidin oral $5,14 \%$, dan ranitidin injeksi $0,86 \%$. (Srikandi, Mukaddas, \& Faustine, 2017). Hasil penelitian Iftitah Alfiyani(2010) tentang Pola Pengobatan Pasien dispepsia di RSD Dr.Soebandi Jember menunjukkan bahwa jumlah golongan obat dispepsia yang paling banyak digunakan adalah Antagonis reseptor H2 60,86\%, Proton pump inhibitor 2,17\%, kombinasi dari Antagonis reseptor $\mathrm{H} 2$ dan PPI $23,91 \%$ beserta pasien yang tidak menggunakan obat dispepsia 15,22\% (Alfiyani, 2010). Setiap tahun gangguan ini mencapai $25 \%$ populasi dunia. Sedangkan menurut data nasional prevalensi dispepsia sekitar 8-30\%. Dan di Indonesia prevalensi dispepsia sekitar 88.599 kasus.
Adanya peran farmasis dalam pola penggunaan obat dispepsia ini adalah untuk mengantisipasi hal-hal yang berkenaan dengan DRPs obat, karena salah satu peran farmasis dalam kegiatan farmasi klinis ini yaitu EPO (Evaluasi Penggunaan Obat) jika nanti sudah ditemukan pola-pola penggunaan obatnya.

Berdasarkan hal di atas maka dilakukan penelitian untuk mengetahui pola penggunaan obat pada pasien dispepsia rawat jalan di RSUD H.Abdul Manap Kota Jambi, yang menjadi gambaran pengobatan semua pasien dispepsia rawat jalan di RSUD $\mathrm{H}$. Abdul Manap Kota Jambi.

\section{B. Metode}

\section{Tempat dan Waktu Penelitian}

Penelitiaan ini dilakukan di bagian rekam medik RSUD H. Abdul manap Kota Jambi pada bulan Agustus-September 2019.

\section{Jenis Penelitian}

Penelitian ini merupakan penelitian deskriptif dengan pengambilan data secara retrospektif dengan pengambilan sampel secara purposive sampling. Penelitian dilakukan untuk melihat pola pengobatan pada pasien dispepsia di instalasi rawat jalan RSUD H. Abdul manap Kota Jambi periode 20172018.

\section{Subyek Penelitian}

Subyek penelitian ini adalah pasien rawat jalan dengan diagnose penyakit dispepsia dengan atau tanpa penyakit penyerta di RSUD H. Abdul Manap Kota Jambi pada periode tahun 2017-2018 yang memenuhi kriteria inklusi dan eksklusi. Adapun kriteria inklusi; a. Jenis kelamin, b. Umur, c. Pekerjaan, d. Bentuk sediaan, e. Golongan Obat, f. Nama obat, g. Jumlah obat perpasien. Kriteria Ekslusi; a. Manifestasi klinik.

\section{Hasil Dan Pembahasan}

Berdasarkan tabel 1 menunjukkan bahwa usia terbanyak yaitu 45 - 60 tahun $(43,42 \%)$ tahun 2017, $(44,44 \%)$ tahun 2018. Pekerjaan Pasien dispepsia yang terbanyak yaitu PNS dengan jumlah $28,95 \%$ (22 pasien) tahun 2017, 30,86\% (25 pasien) tahun 2018.

Berdasarkan karakteristik demografi yang didapat, kejadian dispepsia lebih banyak diderita perempuan daripada laki-laki dikarenakan dispepsia sangat berhubungan 
dengan pola makan, gaya hidup, stres, obat penghilang nyeri maupun akibat infeksi oleh Helycobacter pylori ${ }^{[7]}$. Stres dapat mempengaruhi fungsi hormon yaitu hormon adrenalin, kortisol dan norepinephrine yang dapat meningkatkan sekresi asam lambung, meningkatkan gerakan peristaltik saluran pencernaan sehingga dapat menyebabkan keluhan dispepsia pada akhirnya ${ }^{[8]}$.

Kejadian dispepsia berdasarkan tabel 1 dari segi usia 45 - 60 tahun telah terjadi proses perubahan keadaan di dalam organ tubuh, yang mana organ-organ tubuh mengalami penurunan daya kerja yang berdampak pada ketahanan tubuh sehingga tubuh mudah terserang penyakit seperti rematik, hipertensi, DM, GERD dan lain sebagainya. Seiring bertambahnya usia resiko terkena dispepsia semakin tinggi, dikarenakan kebiasaan yang berhubungan dengan gaya hidup, pola makan dan stress.

Berdasarkan pekerjaan pada tabel 1 diketahui dari segi pekerjaan, PNS lebih banyak ditemui. Hal ini dikarenakan padatnya rutinitas pekerjaan yang dilakukan setiap hari serta kesibukan dalam bekerja maka cenderung mengakibatkan tidak teraturnya pola makan sehingga akan berdampak pada waktu jam makan misalnya sering menunda waktu makan bahkan sampai lupa makan hal ini dapat memicu terjadinya dispepsia ${ }^{[9]}$.

Tabel 1. Karakteristik Demografi pasien Dispepsia.

\begin{tabular}{|c|c|c|c|}
\hline Tahun & Karakteristik Demografi & Jumlah & Persentase \% \\
\hline \multirow{20}{*}{$\frac{\pi}{\stackrel{d}{d}}$} & Jenis kelamin & & \\
\hline & Perempuan & 53 & 69,74 \\
\hline & Laki-laki & 23 & 30,26 \\
\hline & Jumlah & 76 & 100 \\
\hline & Umur & & \\
\hline & $12-18$ & 1 & 1,32 \\
\hline & $19-44$ & 27 & 35,53 \\
\hline & $45-60$ & 33 & 43,42 \\
\hline & $>60$ & 15 & 19,74 \\
\hline & Jumlah & 76 & 100 \\
\hline & Pekerjaan & & \\
\hline & PNS & 22 & 28,95 \\
\hline & IRT & 14 & 18,42 \\
\hline & Swasta & 9 & 11,84 \\
\hline & Wiraswasta & 5 & 6,58 \\
\hline & Pelajar & 4 & 5,26 \\
\hline & Karyawan & 5 & 6,58 \\
\hline & Pensiunan & 2 & 2,63 \\
\hline & Tidak diketahui & 15 & 19,74 \\
\hline & Jumlah & 76 & 100 \\
\hline Tahun & Karakteristik Demografi & Jumlah & Persentase \% \\
\hline \multirow{10}{*}{$\stackrel{\infty}{\stackrel{\sim}{\sim}}$} & Jenis kelamin & & \\
\hline & Perempuan & 56 & 69,14 \\
\hline & Laki-laki & 25 & 30,86 \\
\hline & Jumlah & 81 & 100 \\
\hline & Umur & & \\
\hline & $12-18$ & 4 & 4,94 \\
\hline & $19-44$ & 23 & 28,40 \\
\hline & $45-60$ & 36 & 44,44 \\
\hline & $>60$ & 18 & 22,22 \\
\hline & Jumlah & 81 & 100 \\
\hline
\end{tabular}




\begin{tabular}{clc}
\hline Pekerjaan & & \\
PNS & 25 & 30,86 \\
IRT & 14 & 17,28 \\
Swasta & 12 & 14,81 \\
Wiraswasta & 3 & 3,70 \\
Pelajar & 9 & 11,11 \\
Karyawan & 2 & 2,47 \\
Pensiunan & 4 & 4,94 \\
Tidak diketahui & 12 & 14,81 \\
\hline Jumlah & 81 & 100 \\
\hline dikarenakan riwayat awal penyakit hanya \\
Nyeri epigastrium merupakan & dispepsia tanpa adanya penyakit penyerta \\
ini disebabkan oleh kelainan organ dalam & lainnya. Pasien yang menderita dispepsia \\
ga abdomen kelainan yang muncul akibat & dengan penyakit penyerta yang terbanyak \\
mengkonsumsi makanan yang pedas & yaitu hipertensi. Adanya hipertensi pada kasus \\
dispepsia karena sebelumnya pasien memiliki & riwayat hipertensi.
\end{tabular}

merupakan yang terbanyak ditemukan. Hal ini

Tabel 2. Distribusi Karakteristik Klinik Pasien Dispepsia

\begin{tabular}{cccc}
\hline Tahun & Gejala Klinik & Jumlah Pasien & Persentase(\%) \\
\hline & Nyeri Epigastrium & 21 & 27,63 \\
Mual & 11 & 14,47 \\
Muntah & 3 & 3,95 \\
& Sakit perut & 12 & 15,79 \\
Sakit kepala & 10 & 13,16 \\
Pusing & 7 & 9,21 \\
& Sering sendawa & 1 & 1,32 \\
Demam & 2 & 2,63 \\
& Rasa panas didada & 6 & 3,95 \\
& Tidak diketahui & 76 & 7,89 \\
& Jumlah & 19 & 100 \\
\hline Nyeri Epigastrium & 7 & 23,46 \\
Mual & 7 & 8,64 \\
Muntah & 5 & 8,64 \\
& Sakit perut & 9 & 11,11 \\
& Sakit kepala & 11 & 13,58 \\
Pusing & 1 & 1,23 \\
& Sering sendawa & 2 & 2,47 \\
Demam & 10 & 12,35 \\
& Rasa panas didada & 10 & 12,35 \\
\hline Tidak diketahui & 81 & 100 \\
\hline
\end{tabular}


Tabel 3. Distribusi Penyakit Penyerta

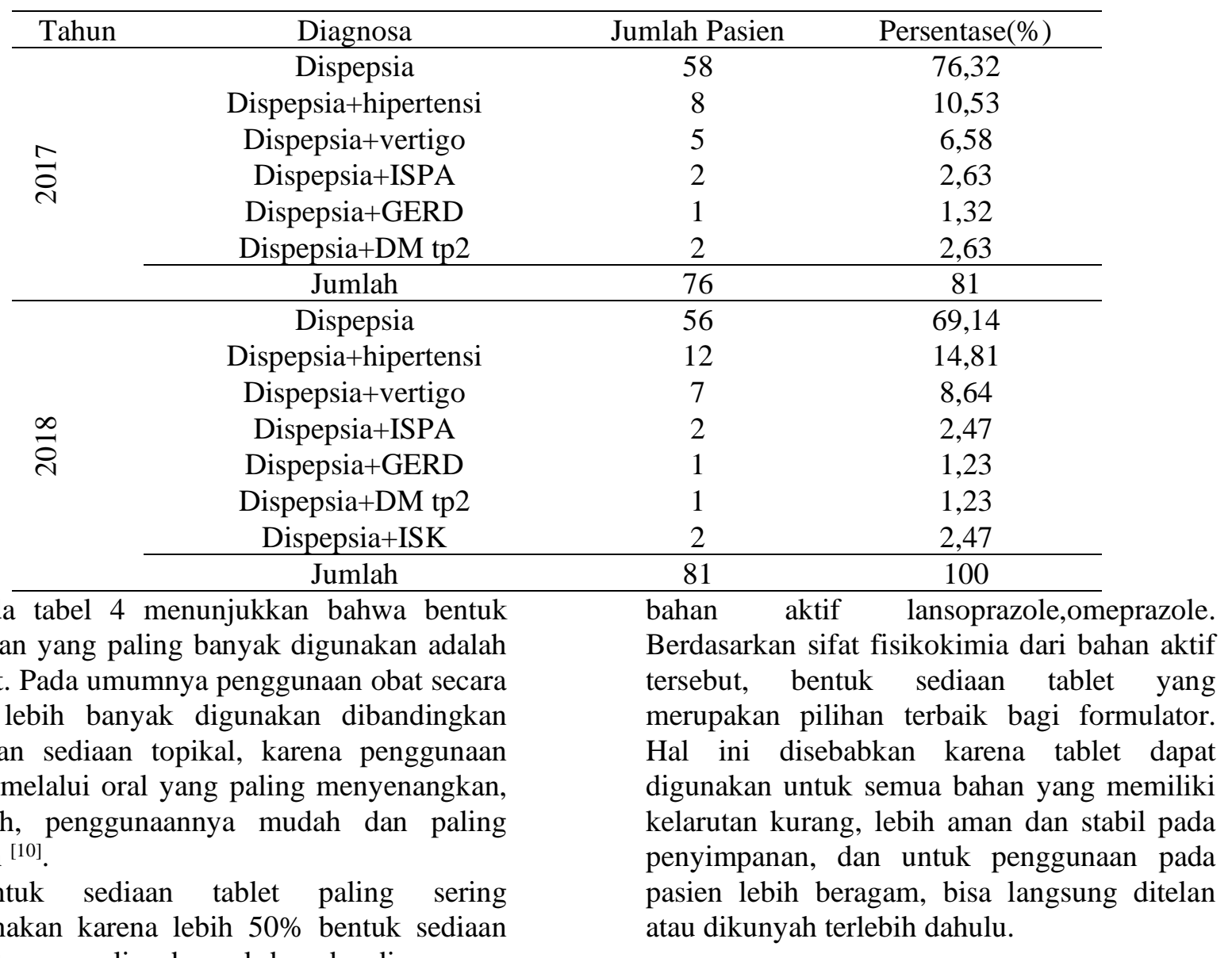

tablet yang paling banyak beredar di pasaran.

Pada tablet untuk dispepsia mengandung

Tabel 4. Jumlah sampel penggunaan obat dispepsia berdasarkan bentuk sediaan

\begin{tabular}{|c|c|c|c|}
\hline Tahun & Bentuk Sediaan & Frek & Persentase $(\%)$ \\
\hline \multirow{4}{*}{ 공 } & Sirup & 74 & 31,48 \\
\hline & Tablet & 155 & 65,97 \\
\hline & Kapsul & 6 & 2,55 \\
\hline & Jumlah & 235 & 100 \\
\hline \multirow{4}{*}{$\frac{\infty}{\stackrel{d}{~}}$} & Sirup & 75 & 31,39 \\
\hline & Tablet & 158 & 66,10 \\
\hline & Kapsul & 6 & 2,51 \\
\hline & Jumlah & 239 & 100 \\
\hline
\end{tabular}

Obat-obat yang paling sering digunakan golongan Pump Proton Inhibitor yaitu lansoprazole dan omeprazole karena efektivitasnya sangat berasa dalam menghambat sekresi asam lambung. Pada kasus ini gejala yang paling banyak dirasakan oleh pasien yaitu nyeri epigastrium, pemberian lansoprazole dan omeprazole digunakan untuk mengurangi gejala yang dirasakan. Lansoprazole, omeprazole digunakan sebagai terapi pemeliharaan dalam waktu yang pendek, karena jika digunakan dalam waktu yang lama akan menambah jumlah bakteri yang dapat hidup didalam lambung tersebut [11].

Untuk penggunaan obat ranitidin dan antasida sering dijadikan terapi kombinasi 
pada pengobatan gastritis, dikarenakan kombinasi ranitidin dan antasida berperan dalam menetralkan asam lambung sehingga dapat mengurangi keluhan nyeri yang dialami pasien [12]. Antasida bekerja dengan cara menetralkan asam dan mematikan pepsin. Antasida tersebut merupakan kombinasi magnesium hidroksida dan alumunium hidroksida, perpaduan dari dua zat ini dapat menghindari efek samping dari masingmasing zat aktif tersebut dimana efek laksatif atau pencahar dari magnesium hidroksida akan mengurangi efek sembelit dari alumunium hidroksida ${ }^{[13]}$.

Sukralfat merupakan jenis golongan obat sitoprotektif yaitu dengan membentuk suatu kompleks yang berbentuk gel dan membran mukus oleh pepsinogen. Tujuan penggunaan sukralfat untuk dapat mengurangi atau mencegah kekambuhan jika digunakan dalam terapi dalam waktu yang lama.

Tabel 5. Jumlah sampel penggunaan obat dispepsia berdasarkan golongan obat dan nama obat

\begin{tabular}{|c|c|c|c|}
\hline Tahun & Golongan Obat & Frek & Persentase $(\%)$ \\
\hline \multirow{12}{*}{ 혹 } & Antasida & 21 & 13,81 \\
\hline & (antasida doen) & & \\
\hline & Antagonis reseptor $\mathrm{H} 2$ & & \\
\hline & (ranitidin) & 1 & 0,66 \\
\hline & Pump Proton Inhibitor & & \\
\hline & (lansoprazole) & 55 & 36,18 \\
\hline & (omeprazole) & 22 & 14,48 \\
\hline & Prokinetik & & \\
\hline & (domperidon) & 5 & 3,29 \\
\hline & Sitoprotektif & & 31,58 \\
\hline & (sucralfat) & 48 & \\
\hline & Jumlah & 152 & 100 \\
\hline \multirow{12}{*}{$\frac{\infty}{i}$} & Antasida & 6 & 3,45 \\
\hline & (antasida doen) & & \\
\hline & Antagonis reseptor $\mathrm{H} 2$ & & \\
\hline & (ranitidin) & - & 0 \\
\hline & Pump Proton Inhibitor & & \\
\hline & (lansoprazole) & 51 & 29,31 \\
\hline & (omeprazole) & 33 & 18,97 \\
\hline & Prokinetik & & \\
\hline & (domperidon) & 16 & 9,19 \\
\hline & Sitoprotektif & & \\
\hline & (sucralfat) & 68 & 39,08 \\
\hline & Jumlah & 174 & 100 \\
\hline
\end{tabular}

Pasien yang menerima $1-3$ variasi jumlah obat yang di berikan kepada pasien berbedabeda hal ini disebabkan karena setiap pasien mempunyai keluhan yang berbeda dan beberapa pasien terdiagnosa mempunyai penyakit penyerta dengan penyakit lain. Untuk variasi jumlah obat antiulkus yang banyak digunakan sebanyak 84,21\% (64 pasien) diberikan kombinasi 2 antiulkus, Tahun 2018 $85,19 \%$ (69 pasien) diberikan kombinasi 2 antiulkus.

Kelas terapi antiulkus adalah terapi utama yang digunakan untuk mengobati masalah gangguan lambung seperti gastritis dan dispepsia yang dimaksudkan untuk menetralkan asam lambung dan meningkatkan pertahanan mukosa lambung. Terapi dispepsia dengan menggunakan obat terutama ditujukan untuk mengobati pasien, mengurangi atau meniadakan gejala sakit, menghentikan atau memperlambat proses penyakit serta mencegah penyakit atau gejala ${ }^{[5]}$. 
Tabel 6. Jumlah variasi obat antiulkus pasien dyspepsia

\begin{tabular}{|c|c|c|c|}
\hline Tahun & Variasi jumlah obat antiulkus & Jumlah pasien & Persentase $(\%)$ \\
\hline \multirow{4}{*}{ 호 } & Tunggal & 10 & 13,16 \\
\hline & Kombinasi 2 antiulkus & 64 & 84,21 \\
\hline & Kombinasi 3 antiulkus & 2 & 2,63 \\
\hline & Jumlah & 76 & 100 \\
\hline \multirow{4}{*}{$\frac{\infty}{\stackrel{\sigma}{\sigma}}$} & Tunggal & 12 & 14,81 \\
\hline & Kombinasi 2 antiulkus & 69 & 85,19 \\
\hline & Kombinasi 3 antiulkus & 0 & 0 \\
\hline & Jumlah & 81 & 100 \\
\hline
\end{tabular}

\section{Simpulan}

Berdasarkan hasil penelitian, dapat ditarik kesimpulan bahwa sampel sebanyak 76 pasien tahun 2017 dan 81 pasien tahun 2018 dari data rekam medik berdasarkan golongan obat Pump Proton Inhibitor (Lansoprazole, Omeprazole) 50,66\% tahun 2017, 48,28\% tahun 2018 yang paling banyak digunakan untuk pengobatan dyspepsia., bentuk sediaan tablet yang paling banyak digunakan $56,97 \%$ tahun 2017, 66,10\% tahun 2018 dengan variasi kombinasi 2 antiulkus yang paling banyak digunakan 86,21\% tahun 2017 dan $85,19 \%$ tahun 2018.

\section{Pustaka}

[1] Fithriyana, R. (2018). Faktor-Faktor Yang Berhubungan Dengan Kejadian Dispepsia Pada Pasien Di Willayah Kerja Puskesmas Bangkinang Kota. PREPOTIF Jurnal Kesehatan Masyarakat, 2(2), 43-54.

[2] Ayu Ruslaini Nasution. (2015). Pola Penggunaan Obat pada Pasien Dispepsia Rawat Inap Tahun 2014 di RSUD Dr. Tengku Mansyur Kota Tanjung Balai.

[3] Sudoyo AW. (2009). Buku ajar ilmu penyakit dalam.

[4] Pardiansyah, R. dkk. (2016). Upaya Pengelolaan Dispepsia dengan Pendekatan Pelayanan Dokter Keluarga Dyspepsia Treatment By Using Family Physician Practice Approach. J Medula Unila, 5(Nomor 2), 1-2.

[5] Srikandi, N., Mukaddas, A., \& Faustine, I. (2017). Profil Penggunaan Obat Pada Pasien Dispepsia Di RSU Anutapura Palu. Farmasi Gelenika, 3(2), 126-131. https://doi.org/10.22487/j24428744.2017.v 3.i2.8772.
[6] Alfiyani, I. (2010). Pola Pengobatan Dispepsia Pada Pasien Rawat Inap di RSD Dr.Soebandi Jember Tahun 2009. Skripsi Universitas Jember.

[7] Nasution Novita, A. E. (2015). HUBUNGAN POLA MAKAN DENGAN KEJADIAN SINDROM DISPEPSIA PADA MAHASISWA FAKULTAS KESEHATAN MASYARAKAT UNIVERSITAS SUMATERA UTARA TAHUN 2015 Novita. 31(2), 259-264

[8] Rahmaika, B. (2014). Hubungan Antara Stres dengan Kejadian Dispepsia di Puskesmas purwodiningratan Jebres Surakarta.

[9] Nugroho, R., Safri, \& Nurchayati, S. (2018). Gambaran Karakteristik Pasien Dengan Sindrom Dispepsia Di Puskesmas Rumbai. JOM FKp, 5(2), 823-830.

[10] Nasif, H., Yuned, M., \& Muchtar, H. (2013). Kajian Penggunaan Obat Intravena Di Smf Penyakit Dalam Rsud Dr. Achmad Mochtar Bukittinggi. Jurnal Sains Dan Teknologi Farmasi, 18(1), 17-27.

[11] Kindiasari, D. (2017). pola penggunaan proton pump inhibitor pada pasien dispepsia.

[12] Isna, W. (2011). Dalam Pengobatan Gastritis Di Smf Penyakit Program Pascasarjana Universitas Andalas Dalam Rumah Sakit Umum Daerah ( Rsud) Ahmad.

[13] Wardaniati, I., Dahlan, A., \& Almahdy, A. (2016). Gambaran Terapi Kombinasi Ranitidin dengan Sukralfat dan Ranitidin dengan Antasida dalam pengobatan gastritis penyakit dalam RSUD Ahmad Mochtar Bukit Tinggi. Jurnal Farmasi, 
8(1), 65-74.

[14] Amelia, R. (2012). Karakteristik Penderita Dispepsia di Instalasi Rawat Inap Penyakit DalamRS Tk. II Dr . A K Gani Palembang Periode JanuariDesember 2011.

[15] Dwigint, S. (2015). the Relation of Diet Pattern To Dyspepsia Syndrom. Jurnal Majority, 4, 73-80.

[16] Lauralee Sherwood. (n.d.). Fisiologi Manusia dari Sel ke Sistem.

[17] Lei, W., Chang, W., \& Wen dkk. (2019). Impact of concomitant dyspepsia and irritable bowel syndrome on symptom burden in patients with gastroesophageal reflux disease. Journal of the Formosan Medical Association, 118(4), 797-806. https://doi.org/10.1016/j.jfma.2018.12.00 2

[18] Moh. Anief. (2010). Ilmu Meracik Obat.

[19] Lina Purnamasari. (2017). faktor risiko,klasifikasi,dan terapi sindrom Dispepsia.

[20] Muya, Y., Murni, A. W., \& Herman, R. B. (2011). Karakteristik Penderita Dispepsia Fungsional yang Mengalami Kekambuhan di Bagian Ilmu Penyakit Dalam RSUP Dr . M . Jurnal, 4(2), 490496.

[21] Nasution Novita, A. E. (2015). HUBUNGAN POLA MAKAN DENGAN KEJADIAN SINDROM DISPEPSIA PADA MAHASISWA FAKULTAS KESEHATAN MASYARAKAT UNIVERSITAS SUMATERA UTARA TAHUN 2015 Novita. 31(2), 259-264.

[22] Natalia, M. (2017). Perbedaan Kejadian Dispepsia pada Pengguna Obat Antiinflamasi Non Steroid ( OAINS) di RSUP . Haji Adam Malik Medan Tahun 2017.

[23] Nur, aini. (2019). Pola Penggunaan Obat pada Pasien Dispepsia Rawat Inap di RSUD Aek Kanopan Kab. Labuhanbatu Utara.

[24] Nuraini Widjajanti. (n.d.). Obat-Obatan.

[25] Park, J. H., Lee, S., Kim, J., \& dkk. (2017). Selecting diagnostic parameters of functional dyspepsia based on pattern identi fi cation?: Step 1 - Systematic literature review and expert consensus process. 13(June), 1-8. https://doi.org/10.1016/j.eujim.2017.06.0 08.

[26] Penelitian, B., \& Pengembangan, D. A. N. (2013). RISET KESEHATAN DASAR.

[27] Prakoso, R. B. (2016). Potensi Interaksi Obat Pada Pasien Gangguan Lambung (Dispepsia, Gastritis, Tukak Peptik).

[28] Pratama, H. (2016). Eradikasi Helicobacter pylori. Cdk-243, 43(8), 592595.

[29] Putri, C. Y., Arnelis, \& Asterina. (2016). Gambaran Klinis dan Endoskopi Saluran Cerna Bagian Atas. Jurnal Kesehatan Andalas, 5(752), 343-348.

[30] Sulistiyawati, I., Arinton, I. G., \& Pramono, H. (2017). Deteksi Resistensi Amoxicillin Helicobacter pylori pada Pasien Dispepsia. Biosfera, 33(3), 102.

[31] Tarigan, C. J. (2003). Perbedaan Depresi Pada Pasien Dispepsia Fungsional dan Dispepsia Organik. Hasil Riset, (6), 132. 